Gut, 1978, 19, 1064-1067

\title{
Is hypergastrinaemia associated with rheumatoid arthritis?
}

\author{
D. R. ROWDEN, I. L. TAYLOR, J. A. RICHTER, R. S. PINALS, AND \\ R. A. LEVINE 2
}

From the Department of Medicine, State University of New York, Upstate Medical Center, Syracuse, New York, and the Center for Ulcer Research and Education, Veterans Administration Center, Los Angeles, California, USA

SUMMARY In an attempt to confirm the reported high incidence of raised serum gastrin levels in patients with rheumatoid arthritis (RA), gastrin concentrations were estimated in 54 patients. Only three patients $(6 \%)$ had basal hypergastrinaemia. The heptadecapeptide (G17) and total carboxylterminal immunoreactive gastrin responses to a standard protein meal were measured by specific radioimmunoassay in these three patients and in nine normogastrinaemic RA patients displaying the same age range. The three hypergastrinaemic patients showed significantly greater and more prolonged G17 and total carboxylterminal immunoreactive gastrin responses to the meal compared with the normogastrinaemic RA patients $(P<0.02)$. Two of these three patients agreed to have an acid output study (pentagastrin $6 \mu \mathrm{g} / \mathrm{kg}$ subcutaneously) and gastric mucosal biopsies taken for histology. Both were found to be achlorhydric and to have atrophic gastritis. This study suggests that basal hypergastrinaemia in RA patients is considerably less common than previously reported and, when present, is associated with achlorhydria. In addition, the incidence of achlorhydria in rheumatoid arthritis is similar to that found in a normal age-matched population.

A high incidence of raised serum gastrin levels has been reported in patients with rheumatoid arthritis (RA), with the gastrin levels at times being in the range of that seen in Zollinger-Ellison syndrome or pernicious anaemia (Rooney et al., 1973, 1976a). This hypergastrinaemia was believed to be unassociated with achlorhydria (Rooney et al., 1976b). Short-term administration of anti-inflammatory drugs does not appear to affect serum gastrin levels (Curtarelli et al., 1977) and so drugs are not considered to be a likely cause of the hypergastrinaemia. Patients with inflammatory diseases other than rheumatoid arthritis, such as systemic lupus erythematosus, osteoarthritis, and ankylosing spondylitis

${ }^{1}$ This study was supported by Grant RR-229 from the General Clinical Research Centers' programme of the Division of Research Resources, National Institutes of Health. A preliminary report of this work has been published in abstract form (Gastroenterology (1977), 72, 1122).

'Address for reprints and correspondence: Dr Robert A. Levine, Department of Medicine, State University Hospital, Upstate Medical Center, 750 East Adams Street, Syracruse, New York, 13210, USA.

Received for publication 4 May 1978 were found to have normal gastrin levels (Rooney $e t$ al., 1976a). The aetiology of the hypergastrinaemia in RA thus remains an enigma.

This study was performed to evaluate the incidence and aetiology of hypergastrinaemia in a group of patients with RA. In those RA patients who were found to have hypergastrinaemia and in matched control RA subjects with normal serum gastrin levels gastrin responses to a standard protein meal were investigated and gastrin analysis and gastric biopsy were performed. The recently described antiserum with specificity for heptadecapeptide gastrin (Dockray and Taylor, 1976) was used, which allowed the concentration in serum of the most potent form of gastrin, G17, to be determined by radioimmunoassay without preceding fractionation on G50 Sephadex columns.

\section{Methods}

Gastrin concentrations were determined on blood samples from 54 RA patients (41 female, 13 male) with definite or classical rheumatoid arthritis by the American Rheumatism Association criteria (Ropes 
et al., 1958). Forty-nine of the 54 patients were seropositive for rheumatoid factor and 35 of 54 had subcutaneous nodules. None of these subjects was on corticosteroid therapy. All 54 patients taking salicylates and non-steroidal anti-inflammatory drugs and 14 patients using levamisole stopped their medications for at least one day before study. Gold injections (11 patients) were not given for at least one week. These patients were seen initially in the outpatient clinic and were either fasting or had had a meal one to two hours before. If a raised serum gastrin were found ( $>40 \mathrm{pmol} / \mathrm{l}$; mean $\pm 2 \mathrm{SD}$ in 60 normal subjects (Taylor, 1976)), the test was repeated on a blood sample taken after the patient had fasted overnight. Fourteen such repeated gastrin tests were carried out.

After an overnight fast, 12 RA patients ate a standard protein meal consisting of two hard-boiled eggs (or its equivalent in broiled hamburger in one subject allergic to eggs), one piece of dry toast (no butter or salt), and $120 \mathrm{ml}$ of water to which were added two bouillon cubes. Blood samples for serum gastrin determinations were drawn at $0,+10,+20$, $+30,+40,+50,+60,+75,+90,+105$, and +120 minutes. The heptadecapeptide (G17) and total carboxylterminal immunoreactive gastrin were determined as described by Dockray and Taylor (1976). In 10 of these RA patients, including two of three hypergastrinaemic subjects who consented to further study, acid output tests were performed (pentagastrin $6 \mu \mathrm{g} / \mathrm{kg}$ subcutaneously) by standard gastric analysis. After an overnight fast, the subjects were intubated with a nasogastric tube and the tip was adjusted to lie in the most dependent portion of the stomach. This position was confirmed radiologically and adequacy of collection was further substantiated by the subsequent recovery after two minutes of at least $80 \%$ of an injected volume of water. Aspiration was performed by continuous pump suction which was interrupted by manual suction and air injection every five minutes to ensure patency of the tube. Mucosal biopsies from multiple sites in the antrum and fundus of the stomach were obtained using the Wood's suction biopsy tube, after gastric analysis. This investigation was approved by the Institutional Review Board for the Protection of Human Subjects of the State University Hospital, Upstate Medical Center. Informed written consent was obtained from each subject.

\section{STATISTICS}

To test for statistical differences in the gastrin responses to the standard meal in the hypergastrinaemic and normogastrinaemic RA patients, two summary variables were chosen: the mean response during the first and second post-prandial hours respectively. Differences between the two groups were tested using the Wilcoxon rank-sum test.

\section{Results}

Only three of the 54 RA patients studied had basal hypergastrinaemia. These three patients (age 39, 51, and 63 years) and nine normogastrinaemic RA patients were further studied and distributed into groups, A and B, based on their fasting serum gastrin levels and response to the protein meal. Group A consisted of the three patients with basal hypergastrinaemia $(90,58$, and $46 \mathrm{pmol} / \mathrm{l}$ total carboxylterminal immunoreactive gastrin). Two of these three patients consented to gastric analysis and were found to be achlorhydric (all pH values $>6.0$, 0 , and $0.04 \mathrm{mEq} \mathrm{H}+$ per hour). Gastric biopsies showed atrophic gastritis in the fundus and normal mucosa in the antrum. The nine group B patients had normal fasting gastrin concentrations (basal gastrin $<40 \mathrm{pmol} / \mathrm{l}$, mean $\pm \mathrm{SE}=17 \pm 3.6 \mathrm{pmol} / \mathrm{l})$. Gastric analyses were performed in eight of these nine patients and were normal $(\mathrm{pH}<2.0$ after maximal pentagastrin stimulation) except for one patient who was achlorhydric. Gastric biopsy results were variable and included normal mucosa in three, mild chronic inflammation in two, mild chronic inflammation with atrophy in two, and acute inflammation in one patient.

Figure 1 shows the total carboxylterminal immunoreactive gastrin response in the three group $A$ patients and the nine group B patients. The total gastrin response was significantly greater $(\mathrm{P} \leq 0.02)$ during the second hour in the group $A$ patients compared with the response in the group $B$ patients. The peak responses in the group A patients were 265, 258 , and $75 \mathrm{pmol} / \mathrm{l}$ which contrasts with the mean \pm SE peak response of $64 \pm 15 \mathrm{pmol} / 1$ in the nine group B patients.

Figure 2 shows the $\mathrm{G} 17$ response in the two groups. The $\mathrm{G} 17$ response in the group $A$ patients was significantly greater $(P \leq 0.02)$ over the whole twohour period of the study. The peak G17 responses in the three group A patients were 133, 195, and 57 $\mathrm{pmol} / \mathrm{l}$. This contrasts with the mean $\pm \mathrm{SE}$ peak G17 response in the group B patients of $37 \pm 5.6 \mathrm{pmol} / \mathrm{l}$. The increments in total gastrin and G17 in response to the standard meal in the group $B$ patients are similar to the responses previously reported in normal subjects (Dockray and Taylor, 1976).

\section{Discussion}

Hypergastrinaemia has been reported in a number of clinical conditions, well-summarised in the recent 


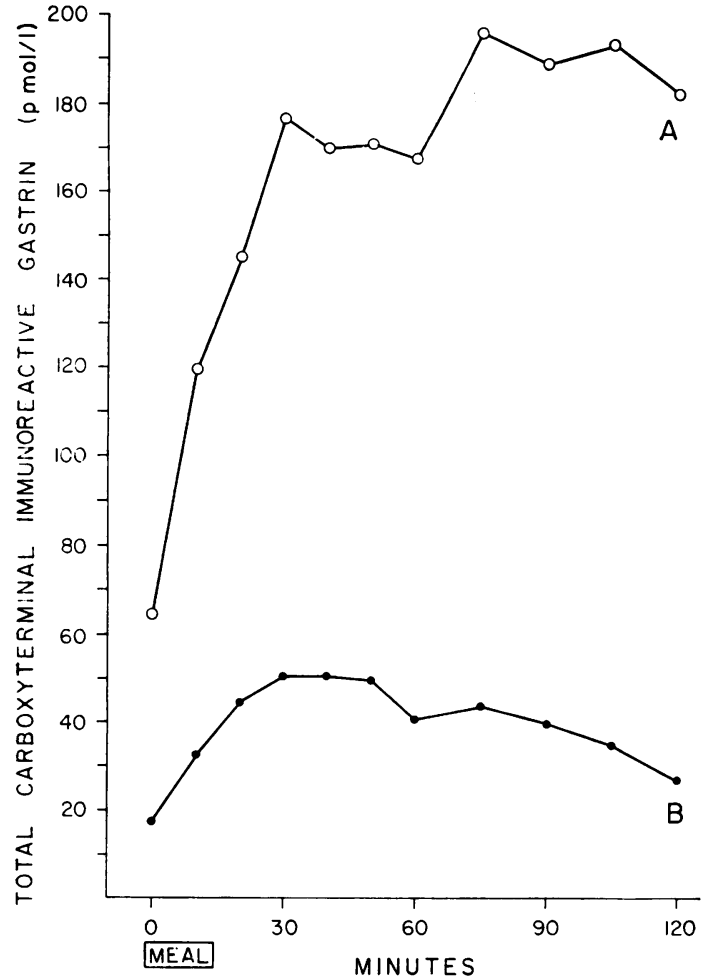

Fig. 1 Total carboxylterminal immunoreactive gastrin response to a standard meal by 1296 antibody in groups $A$ and $B$ patients.

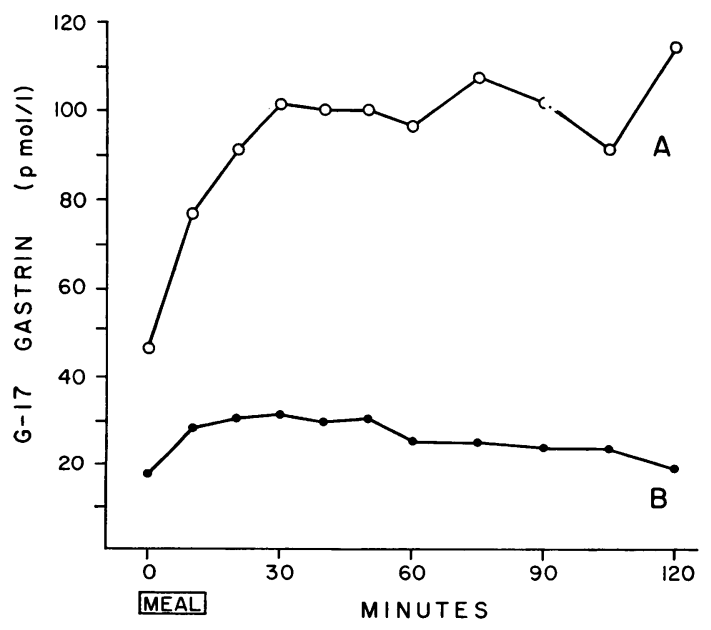

Fig. $2 G 17$ response to a standard meal measured by $L 6$ antibody in groups $A$ and $B$ patients. review by Walsh and Grossman (1975). Included in the list is rheumatoid arthritis. Rooney et al. (1973) first reported the association between RA and raised serum gastrin levels. In their initial report of 50 patients with RA, the mean fasting plasma gastrin level was $171 \pm 38 \mathrm{pg} / \mathrm{ml}$ compared with $56 \pm 8$ $\mathrm{pg} / \mathrm{ml}$ in a control group; eight of these patients had gastrin levels greater than $1000 \mathrm{pg} / \mathrm{ml}$. In a follow-up report Rooney et al. (1976b) reported normal acid outputs in 15 of 16 patients with RA and hypergastrinaemia. Gastric biopsies obtained at the time of gastroscopy were reported to be normal in 18 hypergastrinaemic RA patients.

These results contrast with those of the present study in which we found only three of 54 patients $(6 \%)$ with basal hypergastrinaemia. Among these three patients, the two who consented to gastric analysis and biopsies showed, respectively, achlorhydria and atrophic gastritis. Only one of eight normogastrinaemic RA subjects studied was achlorhydric. This low incidence of achlorhydria in rheumatoid arthritis is similar to that found in a normal age-matched population (Grossman et al., 1963). Our data suggest that hypergastrinaemia in the RA population is related to the presence of achlorhydria, rather than to some other unexplained phenomenon.

We cannot explain why our results differ completely from Rooney et al. (1973, 1976a, 1976b). It is possible that the apparent discrepancy between the findings of this study and that of Rooney et al. (1976a) might be explained by the difference in crossreactivity of the antisera used. However, details of the specificity of the antiserum used in the study of Rooney and his colleagues (1976a) were not given, which makes this hypothesis difficult to evaluate. It is also unlikely that interpretation of antral and fundic histology and acid output could be at variance between the two studies. It is of interest that Rooney (1976b) only sampled gastric mucosa obtained from the body of the stomach, while we biopsied both body and antrum. While a smaller biopsy sample cannot conclusively exclude the presence of chronic atrophic gastritis, there was no suggestion of such a lesion by their histological and acid output data. Rooney et al. (1976b) used both betazole and pentagastrin stimulation and we used the latter stimulant in the same dose as in their study. Other remote possibilities to account for the differences could include population variables such as the severity and duration of disease, the titre of rheumatoid and antinuclear factors, and the drugs used. These variables are unlikely to explain the markedly divergent results between these two studies. Moreover, in our study the incidence of age, sex ( $75 \%$ female), seropositivity for rheumatoid factor 
$(91 \%)$, and nodule formation $(65 \%)$ are essentially similar to the group studied by Rooney et al. (1973, 1976a, 1976b) in Ireland.

Basal gastrin concentrations measured by the G17 specific antibody in the group $B$ patients approximated the apparent total carboxylterminal immunoreactive gastrin (Figs. 1 and 2). This observation is similar to the findings in normal subjects when basal gastrin concentrations are measured with these same two antisera (Dockray and Taylor, 1976). Immunosorption studies in these normal subjects indicated that a large proportion of basal immunoreactivity measured with both antisera represented nonspecific inhibition of binding of labelled gastrin to antibody. However, the non-specific inhibitory factors did not increase after feeding, suggesting that the increment in G17 and total carboxylterminal immunoreactive gastrin after food represents true immunoreactive gastrin.

The gastrin responses to a standard protein meal in the hypergastrinaemic RA patients were different when compared with normogastrinaemic RA patients, in that G17 and total carboxylterminal immunoreactive gastrin responses were significantly greater and more prolonged than that observed in the normogastrinaemic patients. The results indicate that RA patients with normal basal gastrin concentrations have a normal G17 and total carboxylterminal immunoreactive gastrin response to a standard meal. In contrast, RA patients with basal hypergastrinaemia show a much greater increase in both $\mathrm{G17}$ and total carboxylterminal immuno- reactive gastrin response to the standard meal, which would appear to be the result of lack of acid inhibition of gastrin release.

\section{References}

Curtarelli, G., Caldara, R., and Bierti, L. (1977). Effect of anti-inflammatory agents on serum gastrin concentrations (Letter). Annals of the Rheumatic Diseases, 36, 97.

Dockray, G. J., and Taylor, I. L. (1976). Heptadecapeptide gastrin: measurement in blood by specific radioimmunoassay. Gastroenterology, 71, 971-977.

Grossman, M. I., Kirsner, J. B., and Gillespie, I. E. (1963). Basal and histalog-stimulated gastric secretion in control subjects and in patients with peptic ulcer or gastric cancer. Gastroenterology, 45, 14-26.

Rooney, P. J., Grennan, D. M., Sturrock, R. D., Brooks, P. M., and Dick, W. C. (1976a). Serum immunoreactive gastrin: specificity for rheumatoid arthritis, bimodality of distribution, and failure of effect of anti-inflammatory drugs. Annals of the Rheumatic Diseases, 35, 40-45.

Rooney, P. J., Kennedy, A. C., Gray, G. H., Sturrock, R. D., Buchanan, K. D., and Dick, W. C. (1976b). Serum immunoreactive gastrin in rheumatoid arthritis. Annals of the Rheumatic Diseases, 35, 246-250.

Rooney, P. J., Vince, J., Kennedy, A. C.. Webb, J., Lee, P., Dick, W. C., Buchanan, K. D., Hayes, J. R., Ardill, J., and O'Connor, F. (1973). Hypergastrinaemia in rheumatoid arthritis: disease or iatrogenesis. British Medical Journal, 1, 752-753.

Ropes, M. W., Bennett, G. A., Cobb, S., Jacox, R., and Jessar, R. A. (1958). Revision of diagnostic criteria for rheumatoid arthritis. Bulletin on Rheumatic Diseases, 9, 175-176.

Taylor, I. L. (1976). Region specific antibodies and the study of gastrin. Ph.D. Thesis, Liverpool University.

Walsh, J. H., and Grossman, M. I. (1975). Gastrin. New England Journal of Medicine, 292, 1324-1344, 1377-1384. 